\title{
Avaliação macroscópica da exposição ao etanol e da desintoxicação alcoólica sobre lesões gástricas em ratos
}

\author{
Macroscopic assessment of exposure to ethanol and alcoholic detoxification \\ on gastric lesions in rats
}

\begin{abstract}
André Luiz Thomaz de Souza1, Renato de Oliveira Horvath², Fábio de Souza Terra³ , José Antônio Dias Garcia, Ana Maria Duarte Dias Costa ${ }^{5}$, Evelise Aline Soares ${ }^{6}$

${ }^{1}$ Mestrando em Enfermagem pela Universidade Federal de Alfenas (UNIFAL), Alfenas, MG; ${ }^{2}$ Mestrando em Biociências Aplicada a Saúde pela UNIFAL, Alfenas, MG; ${ }^{3}$ Doutor em Enfermagem Fundamental e Docente no Departamento de Enfermagem da UNIFAL, Alfenas, MG; ${ }^{4}$ Doutor em Biologia Funcional e Molecular pela Universidade Estadual de Campinas (UNICAMP) e Docente nos Cursos de Odontologia e Medicina da Universidade José do Rosário Vellano (UNIFENAS), Alfenas, MG; ${ }^{5}$ Doutora em Farmacologia pela UNICAMP e Docente no Curso de Odontologia da UNIFENAS, Alfenas, MG; ${ }^{6}$ Doutora em Anatomia Humana pelo programa de Biologia Celular e Estrutural da UNICAMP e Docente no Departamento de Anatomia da UNIFAL, Alfenas, MG.
\end{abstract}

\section{RESUMO}

Objetivos: Investigar os efeitos do consumo crônico de etanol e da desintoxicação alcoólica sobre o aspecto macroscópico em lesões gástricas em ratos.

Métodos: Trata-se de estudo experimental no qual foram utilizados 18 ratos machos adultos (Rattus novergicus) da linhagem Wistar, com 40 dias de vida, divididos em três grupos aleatórios com seis animais cada: Grupo Controle (CT), Grupo Desintoxicado (DE) e Grupo Alcoólico (AC). Os animais do grupo AC foram submetidos a um modelo experimental denominado alcoolista crônico, em que, após um período de adaptação receberam etanol como único alimento liquido disponível até completar 13 semanas de experimento. Os animais do grupo DE foram submetidos ao mesmo protocolo que o grupo $\mathrm{AC}$, no entanto, ao completarem seis semanas de consumo alcoólico, foram submetidos ao processo de desintoxicação alcoólica. Ao final do experimento coletaram-se os estômagos dos animais dos três grupos para investigação da presença de lesões gástricas.

Resultados: Os animais do grupo CT não apresentaram lesões. Os animais do grupo DE, em comparação com os do grupo AC, exibiram um número maior de lesões gástricas (44 $\pm 3,7$ e $21 \pm 0,3$ respectivamente). A análise macroscópica dos estômagos indica que os animais do grupo DE foram os que apresentaram maior índice de lesões na mucosa gástrica.

Conclusões: O etanol consumido de forma crônica ou após a desintoxicação alcoólica desencadeou lesões gástricas nos grupos AC e DE, porém de forma mais acentuada no grupo submetido à desintoxicação, o que pode caracterizar um possível sinergismo entre consumo de etanol e o estresse pós-desintoxicação alcoólica na patogenia da úlcera gástrica.

DESCRITORES: ALCOOLISMO; DESINTOXICAÇÃO; ÚLCERA GÁSTRICA.

\section{ABSTRACT}

Aims: To investigate the effects of chronic ethanol consumption and alcohol detox on macroscopic gastric lesions in rats.

Methods: This is an experimental study in which 18 adult male rats (Rattus norvegicus) of the Wistar strain, with 40 days of life were divided into three randomized groups with six animals each: Control Group (CT), Detoxicated Group (DE) and Alcohol Group (AC). The AC animals have been subjected to an experimental model termed as chronic alcoholics, in which, after a period of adaptation, they received ethanol as the only liquid food available until completion of 13 weeks of the experiment. The DE was subjected to the same protocol as the AC, however, after six weeks of alcohol consumption, the animals were subjected to the alcohol detoxification process. At the end of the experiment, the stomach of the three groups of animals were collected in order to investigate the presence of gastric lesions.

Results: The animals in the CG showed no lesions. The animals in DE exhibited a larger number of lesions in comparison to the AC (44 \pm 3.7 and $21 \pm 0.3$ respectively). Macroscopic examination of the animal's stomachs indicates that the animals in the DE were those with the highest injury rate in the gastric mucosa.

Conclusions: Ethanol consumed chronically or after alcohol detoxification triggered gastric lesions in AC and DE, but sharply in the group submitted to detoxification, which can characterize a possible synergism between ethanol consumption and alcohol detox post-stress in the pathogenesis of gastric ulcer.

KEY WORDS: ALCOHOLISM; DETOXIFICATION; GASTRIC ULCER. 


\section{INTRODUÇÃO}

Para a Organização Mundial da Saúde ${ }^{1}$ o uso abusivo de bebidas alcoólicas é considerado um dos principais desafios a ser enfrentado no atendimento à saúde pública. Tal situação desperta a atenção dos profissionais da saúde e dos órgãos governamentais em diversos países. ${ }^{2}$ A dependência química gerada pelo etilismo e, consequentemente, o surgimento da doença crônica progressiva característica da doença, ocorre em função do principal componente químico encontrado nas bebidas alcoólicas, o etanol. ${ }^{3}$

No Brasil, a dimensão territorial acarreta dificuldades para generalizar estudos epidemiológicos sobre o consumo de etanol, principalmente em função das diferenças sociais, econômicas e culturais de cada região. ${ }^{4}$ No entanto, de acordo com o Primeiro Levantamento Nacional sobre os Padrões de Consumo de Álcool na População Brasileira, ${ }^{5}$ dentre 3.007 entrevistados de norte a sul do País, $52 \%$ dos indivíduos acima de 18 anos ingerem bebidas alcóolicas ao menos uma vez no ano, sendo que neste mesmo grupo, $11 \%$ dos indivíduos consumem bebidas alcoólicas diariamente.

O etanol age como elemento tóxico aos tecidos corporais, ${ }^{2}$ causando, entre outras, importantes alterações na mucosa gastrointestinal. ${ }^{6}$ De acordo com o consenso sobre a síndrome da abstinência do álcool, ${ }^{7}$ as principais comorbidades clínicas do sistema gastrointestinal associadas ao consumo de bebidas alcoólicas são pancreatite crônica, esteatose hepática, hepatite alcoólica, hemorragia digestiva, cirrose hepática com ou sem hepatite alcoólica, gastrite, úlceras pépticas, esofagite de refluxo e tumores. Além dos efeitos do etanol sobre a mucosa gástrica, o estresse relacionado à dependência química ou até mesmo à abstinência alcoólica, podem causar lesões pré-neoplásicas e ulcerações gástricas. ${ }^{8}$

Dentre as múltiplas etiologias que podem levar a úlcera gástrica, o etilismo evidencia-se como um importante fator de risco associado à doença. ${ }^{9}$ Estudos em modelos animais demonstram efeitos nocivos do consumo de álcool sobre o trato gastrointestinal em animais submetidos ao alcoolismo experimental. ${ }^{10-13}$ Diante do exposto e do reduzido número de investigações nesta área, compreende-se a real necessidade de novos estudos que possam abordar o consumo do etanol e seus agravos aos tecidos biológicos, principalmente em relação à atividade ulcerogênica dessa substância. Desse modo, o objetivo do estudo foi investigar os efeitos do consumo crônico de etanol e da desintoxicação alcoólica sobre o aspecto macroscópico de lesões gástricas em ratos.

\section{MÉTODOS}

\section{Protocolo animal}

Foi realizado um estudo experimental que incluiu 18 ratos adultos machos (Rattus novergicus) da linhagem Wistar, com 40 dias de vida e peso médio de $179 \pm 2,5 \mathrm{~g}$, provenientes do biotério dos cursos de pósgraduação da Universidade José do Rosário Vellano (UNIFENAS). O estudo foi realizado no ano de $2012 \mathrm{e}$ os animais permaneceram durante todo o experimento no laboratório de fitofarmacologia da UNIFENAS, em estantes ventiladas (Alesco ${ }^{\circledR}$, Monte Mor - SP/Brasil) com controle de temperatura e controle de 12 horas no ciclo claro/escuro, em caixas para roedores com forração de maravalha.

Os animais foram divididos aleatoriamente em três grupos experimentais, com seis animais em cada: Grupo Controle (CT), cujos animais receberam dieta líquida com água ad libitum; Grupo Alcoólico (AC), no qual os animais seguiram um modelo experimental de alcoolismo crônico denominado "semi-voluntário", em que o álcool foi o único alimento líquido disponível. Nesse modelo, primeiramente os animais passaram por um breve período de adaptação gradativa ao álcool, ${ }^{14,15}$ recebendo, por uma semana, dieta líquida à base de álcool etílico $5 \%$ e $10 \%$ e, a partir da terceira semana, álcool etílico a $15 \%$, permanecendo com essa dieta até a $13^{\mathrm{a}}$ semana; e Grupo Desintoxicado (DE), no qual os animais foram submetidos ao mesmo protocolo que o grupo AC, no entanto, ao completarem seis semanas de administração de etanol $15 \%$ na dieta líquida oferecida, os animais passaram por um breve período de desadaptação gradativa ao álcool, recebendo dieta líquida à base de álcool etílico a $10 \%$, a 5\%, uma semana cada, e posteriormente permaneceram com dieta líquida à base de água ad libitum até completarem 13 semanas de experimento. Após essa etapa, os animais foram considerados como desintoxicados, protocolo este baseado no estudo de Horvath et al. ${ }^{16}$ (Tabela 1).

Todos os animais receberam a mesma dieta sólida (Nuvilab ${ }^{\circledR}$, São Paulo, SP). A cada 48 horas foram realizadas pesagem dos animais, trocas de dieta líquida com nova diluição do etanol e mensuração do consumo de dieta líquida e sólida para cálculo da ingestão média. Ao término da $13^{\circ}$ semana, todos os animais foram submetidos ao protocolo de eutanásia por meio de overdose anestésica por via intraperitoneal, utilizan- 
Tabela 1. Protocolo do estudo experimental no qual foram utilizados 18 ratos machos adultos (Rattus novergicus) da linhagem Wistar, para verificar a ação do etanol e da desintoxicação alcoólica sobre a mucosa gástrica.

\begin{tabular}{|c|c|c|c|c|}
\hline \multirow{2}{*}{ Grupos } & \multicolumn{4}{|c|}{ Protocolo experimental } \\
\hline & $1 \stackrel{a}{-} 4^{a}$ semana & $5^{a}-10^{a}$ semana & $11^{a}-13^{a}$ semana & Final da $13^{a}$ semana \\
\hline $\mathrm{CT}$ & Água & Água & Água & eutanásia \\
\hline AC & Etanol (0-5-10-15\%)* & Etanol (15\%) & Etanol (15\%) & eutanásia \\
\hline DE & Etanol (0-5-10-15\%)* & Etanol $(15 \%)$ & Etanol $(10-5-0 \%)^{* *}$ & eutanásia \\
\hline
\end{tabular}

CT: Grupo Controle; AC: Grupo Alcoólico; DE: Grupo Desintoxicado.

* Período de adaptação; ** Período de desintoxicação, correspondendo a diferentes concentrações alcóolicas a cada semana.

do-se de solução de xilazina/ketamina (Francotar ${ }^{\circledR}$, Virbaxy $1^{\circledR} 2 \%$, São Paulo, SP) na concentração de 0,30 $\mathrm{ml}$ para cada 100 gramas de peso animal.

Este estudo foi aprovado pelo Comitê de Ética da UNIFENAS, sob o parecer de número 19A/2007. $\mathrm{O}$ estudo cumpriu todas as exigências em relação ao bem-estar animal, conforme as normas do Colégio Brasileiro de Experimentação Animal.

\section{Coleta dos estômagos e registro fotográfico}

Logo após a eutanásia os animais foram colocados em decúbito dorsal e foi realizada uma incisão longitudinal mediana na parede abdominal, expondo as vísceras. $\mathrm{O}$ estômago foi removido, mantido em placa de Petri, lavado e aberto ao longo da curvatura menor. O conteúdo gástrico foi desprezado, a mucosa foi lavada delicadamente com água destilada e esticada em placa de isopor. Posterior à fixação no isopor, os estômagos foram fotografados com auxilio de uma câmera fotográfica Sony ${ }^{\circledR}$ modelo HX300 (São Paulo, SP), resolução de 20.4 MP e sem zoom óptico, fixada em um tripé com a lente voltada para a peça anatômica a uma distância de $20 \mathrm{~cm}$.

\section{Determinação do índice de lesões gástricas}

O índice de úlceras foi determinado por meio da "leitura cega", ou seja, o pesquisador responsável pela quantificação das lesões gástricas não tinha conhecimento sobre a distribuição dos grupos avaliados. ${ }^{17}$ Ressalta-se que o pesquisador envolvido nessas avaliações detém conhecimento técnico e científico aprimorado sobre as estruturas analisadas.

Para a contagem ou pontuação das lesões, seguiu-se a seguinte fórmula: lesões $\leq 1 \mathrm{~mm}=1$ ponto; lesões $\geq 1 \mathrm{~mm}=1,5$ ponto $\times$ comprimento da lesão em $\mathrm{mm}$; e úlceras perfuradas $=5$ pontos $\times$ comprimento da lesão em mm). ${ }^{17}$ A visualização dos estômagos foi realizada com auxílio de uma lupa estereomicroscópica binocular $\left(\right.$ Tecnival $\left.^{\circledR}\right)$ com amplitude de $10 \times$.

\section{Análise morfométrica das úlceras}

As fotografias dos estômagos, obtidas conforme descrito anteriormente, foram digitalizadas e, com o auxílio do programa ImageLab ${ }^{\circledR}$, foram determinados os números de úlceras, medidas da área de cada lesão e área total das respectivas mucosas gástricas. ${ }^{18}$

\section{Análise Estatística}

Os dados coletados foram expressos em média \pm erro padrão da média (EPM) e a comparação estatística entre os grupos de estudo foi realizada por meio do Teste de Tukey-Kramer. Os resultados foram considerados significativos para $\mathrm{p} \leq 0,05$.

\section{RESULTADOS}

O consumo líquido e sólido foi satisfatório entre os grupos, no entanto, os animais dos grupos DE e $\mathrm{AC}$ ingeriram menor quantidade de dieta líquida em comparação com os animais do grupo CT $(38 \pm 0,5$, $36,2 \pm 2,0$ e $45 \pm 1,5$ respectivamente). O consumo de dieta sólida foi menor nos animais do grupo DE quando comparados com os animais dos grupos CT e AC $(38,9 \pm 0,5,49,4 \pm 1,07$ e 41,7 $\pm 3,5$ respectivamente). Durante o experimento os animais ganharam peso, sem diferenças significativas entre os grupos, com um consumo médio superior a $25 \mathrm{~g}$ de ração e $15 \mathrm{ml}$ de água por dia.

A análise do índice de úlceras somente pôde ser realizada nos animais dos grupos $\mathrm{AC}$ e $\mathrm{DE}$, em virtude de que os animais do grupo CT não apresentaram ulcerações. Os animais do grupo DE em comparação com os do grupo AC exibiram um número maior de lesões gástricas (44 $\pm 3,7$ e 21 $\pm 0,3$ respectivamente) e, consequentemente, maior pontuação (Tabela 2 ). 
Tabela 2. Resultados encontrados nos diferentes grupos de ratos machos adultos (Rattus novergicus) da linhagem Wistar, em estudo experimental para verificar a ação do etanol e da desintoxicação alcoólica sobre a mucosa gástrica.

\begin{tabular}{|lccc|}
\multicolumn{1}{c}{ Variáveis } & $\begin{array}{c}\text { Grupos de estudo } \\
\text { (grupo controle) } \\
\mathbf{N = 6}\end{array}$ & $\begin{array}{c}\text { DE } \\
\text { (grupo desintoxicado) } \\
\mathbf{N = 6}\end{array}$ & $\begin{array}{c}\text { AC } \\
\text { (grupo alcoólico) } \\
\mathbf{N = 6}\end{array}$ \\
\hline Ganho de peso & $267 \pm 2,0^{\mathrm{a}}$ & $264 \pm 5,7^{\mathrm{a}}$ & $263 \pm 2,0^{\mathrm{a}}$ \\
\hline Consumo de líquido $(\mathrm{mL})$ & $45 \pm 1,5^{\mathrm{a}}$ & $38 \pm 0,5^{\mathrm{b}}$ & $36,2 \pm 2,0^{\mathrm{b}}$ \\
\hline Consumo de sólido $(\mathrm{g})$ & $49,4 \pm 1,07^{\mathrm{a}}$ & $38,9 \pm 0,5^{\mathrm{b}}$ & $41,7 \pm 3,5^{\mathrm{a}}$ \\
\hline Índice de lesões gástricas & $0 \pm 0^{\mathrm{a}}$ & $3 \pm 0,52^{\mathrm{b}}$ & $1,7 \pm 0,2^{\mathrm{c}}$ \\
\hline Número de úlceras & $0 \pm 0^{\mathrm{a}}$ & $44 \pm 3,7^{\mathrm{b}}$ & $21 \pm 0,3^{\mathrm{c}}$ \\
\hline Área total de ulceração & $0 \pm 0^{\mathrm{a}}$ & $179 \pm 35^{\mathrm{b}}$ & $155 \pm 15^{\mathrm{c}}$ \\
\hline
\end{tabular}

Duas médias, seguidas pela mesma letra pequena, não são diferentes entre si $(P \leq 0,05)$ ao teste de Tukey. Os resultados são apresentados como média \pm EPM (erro padrão da média).

Os animais do grupo CT não apresentaram lesões gástricas, sinais de hiperemia ou hemorragia, enquanto os animais dos grupos $\mathrm{AC}$ e DE, além das regiões com lesões gástricas pontuadas por meio do índice de lesão gástrica, também exibiram mucosa hiperêmica. No grupo DE um animal apresentou área hemorrágica na região antro gástrica. A análise macroscópica dos estômagos indicou que os animais do grupo DE foram os que apresentaram maior área de lesão na mucosa gástrica (Figura 1).
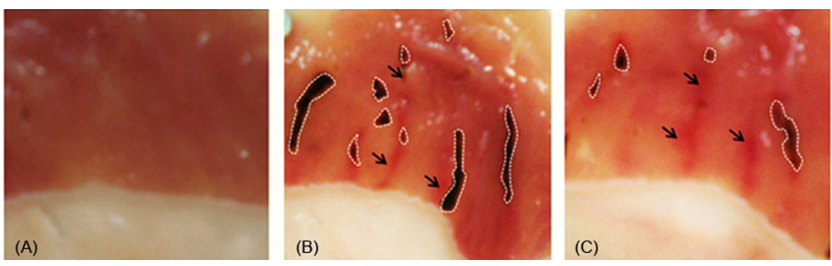

Figura 1. Mucosa gástrica observada por meio de registro fotográfico: A) estômago de um animal do grupo CT (controle), observando-se ausência de lesões na mucosa; B) estômago de um animal do grupo DE (desintoxicado), observando-se um número acentuado de ulcerações, circundadas por linha pontiIhada, e áreas de hiperemia da mucosa (setas); C) estômago de um animal do grupo AC (alcoólico), observando-se ulcerações, circundadas por linha pontilhada, e áreas de hiperemia da mucosa (setas).

\section{DISCUSSÃO}

Os resultados apresentados neste estudo evidenciam que o consumo crônico de etanol a $15 \%$ e/ou a desintoxicação alcoólica propiciaram o surgimento de lesões gástricas com intensidades diferentes. Observou-se uma diminuição no consumo de dieta líquida e sólida pelos animais, no entanto sem caracterizar desnutrição proteica ou desidratação. Assim, as alterações gástricas observadas podem ser atribuídas exclusivamente aos efeitos tóxicos do etanol.

Ressalta-se que o consumo diário de ração e água por todos os grupos descaracteriza a desnutrição e desidratação. ${ }^{19}$ Em que, o controle da ingestão líquida e sólida durante o experimento é fundamental, uma vez que o consumo sólido e líquido ineficaz pode levar a desnutrição proteica e desidratação, influenciando de forma negativa os resultados, em função de que tal evento induz as respostas teciduais na busca por um equilíbrio interno. ${ }^{20}$

Diferentes metodologias com o uso de concentrações variadas e tempo de exposição ao etanol são utilizadas para avaliar os seus efeitos nos tecidos corporais. Estudos referentes ao alcoolismo experimental utilizaram concentrações de etanol que variam de 10 a $30 \%$ em períodos de 4 a 12 semanas., ${ }^{2,1421}$ Destaca-se que o protocolo animal utilizado neste estudo foi suficiente para ocasionar as lesões gástricas, não ocasionando overdose nem morte dos animais durante o experimento.

O estômago apresenta muitas funções, como motilidade, digestão, secreção ácida e controle dos mecanismos de defesa por meio da mucosa gástrica, além de manter o tônus do esfíncter esofágico e pilórico. ${ }^{22}$ No entanto, a mucosa gástrica permanece em exposição a diferentes situações que podem levar a lesões e descontinuidade em sua superfície, ou ulcerações. ${ }^{23}$ Estudos apontam que os fatores fisiopatológicos das ulcerações no trato gastrointestinal, em especial na mucosa gástrica, estão associados principalmente à infecção causada pela bactéria gram-negativa Helicobacter pylori, ao uso de antiinflamatórios não-esteroides e ao estresse emocional, bem como aos hábitos tabagismo e etilismo. ${ }^{24-26}$ 
É fundamental enfatizar a descoberta sobre o papel de Helicobacter pylori no desenvolvimento das lesões gástricas, pois que aproximadamente $70 \%$ destas estão associadas com a presença da bactéria. ${ }^{24}$ Por outro lado, é preciso investigar o mecanismo de diferentes situações que possam ocasionar e/ou potencializar lesões gástricas, dentre as quais o uso abusivo das bebidas alcóolicas.

Os resultados do índice de lesões gástricas evidenciam os efeitos agressivos do etanol na parede gástrica dos animais dos grupos $\mathrm{AC}$ e $\mathrm{DE}$ em comparação com o grupo CT. O grupo AC apresentou um índice de lesão gástrica inferior ao grupo $\mathrm{DE}$; este achado deve-se à alta capacidade de regeneração do epitélio gástrico, o que é consonante com o estudo ultraestrutural da mucosa gástrica exposto ao etanol realizado por Arabski et al. ${ }^{27}$ Melo-Junior et al. ${ }^{11}$ apontam que a ingestão crônica do álcool favorece uma resposta adaptativa das membranas, apesar da interação álcool-membrana ocasionar mudanças significativas no funcionamento das mesmas.

Os animais do grupo DE apresentaram lesões na mucosa gástrica mais acentuadas, mesmo perante a eliminação do consumo de etanol. Este achado sugere que as lesões observadas neste grupo podem ser decorrentes da agressão do etanol durante o período de alcoolismo experimental e/ou do estresse ocasionado pela desintoxicação alcoólica. De acordo com a Associação Brasileira de Estudos sobre o Álcool e outras Drogas (ABAD) ${ }^{28}$ a abstinência alcoólica é marcada com um período de intensas modificações orgânicas e acentuado estresse emocional. Um estudo clássico de Miller $^{29}$ já mostrava que as úlceras provocadas por estresse ocorrem por fatores psicológicos e fisiológicos. $\mathrm{O}$ estresse induz a peroxidação de lipídeos a partir do aumento dos níveis de peroxidase lipídica. ${ }^{18} \mathrm{~A}$ consequência desse processo é o aumento da geração de espécies livres de oxigênio reativo, ocasionando lesão oxidativa que é considerada fator comum na patogenia de diferentes modelos experimentais e clínicos de úlcera. ${ }^{30}$

Apesar das limitações do estudo no que diz respeito à avaliação do estresse nos grupos experimentais, conclui-se por um possível efeito sinérgico entre o estresse da desintoxicação alcóolica e o efeito lesivo do etanol no desenvolvimento de úlcera gástrica. A investigação científica sobre os efeitos tóxicos relacionados ao consumo crônico do etanol é de grande importância, principalmente quando se pensa na saúde do trato gastrointestinal. O desenvolvimento de novos estudos utilizando diferentes concentrações alcoólicas, períodos de exposição e alocação de grupos de estresse, fazem-se necessários na busca por respostas sobre alcoolismo, estresse e úlcera gástrica.

\section{REFERÊNCIAS}

1. World Health Organization. WHO Global Status Report on Alcohol. Department of Mental Health and Substance Abuse. Geneva: World Health Organization; 2004.

2. Soares EA, Favaro WJ, Cagnon VHA, Bertran CA, Camilli JA. Effects of alcohol and nicotine on the mechanical resistance of bone and bone neoformation around hydroxyapatite implants. J Bone Miner Metab. 2010;28(1):101-7.

3. Lima CC1, Silva TD, Santos L, Nakagaki WR, Loyola YC, Resck MC, Camilli JA, Soares EA, Garcia JA. Effects of ethanol on the osteogenesis around porous hydroxyapatite implants. Braz J Biol. 2011 Feb;71(1):115-9.

4. Matos AM, Carvalho RC, Costa COM, Gomes KMPS, Santos LM. Consumo frequente de bebidas alcoólicas por adolescentes escolares: estudo de fatores associados. Rev Bras Epidemiol. 2010;13(2):302-13.

5. Laranjeira R, Duarte PCAV. I Levantamento Nacional sobre os padrões de consumo de álcool na população brasileira. Brasília (DF): Secretaria Nacional Antidrogas; 2007.

6. Seitz HK, Homann N. Effect of alcohol on the orogastrointestinal tract, the pancreas and the liver. In: Heather N, Peters TJ, Stockwell T. International Handbook of Alcohol Dependence and Problem. Chichester: John Wiley \& Sons; 2001. p. 151-67.

7. Laranjeira R, Nicastri S, Jerônimo C, Marques AC, Gigliotti A, Campana A, Bezerra B, Maciel C, Del Bem C, Requião D, Luz E, Souza FGM, Kerr-Correa F, Dias JC, Bou-Habib JC, Zaleski M, Zago MP, Nóbrega P, Mussi R, Palhano R, Ramos SP. Consenso sobre a síndrome de abstinência do álcool (SAA) e o seu tratamento. Rev Bras Psiquiatr. 2000;22(2):62-71.

8. Madrid JF, Leis O, Díaz-Flores L, Sáez FJ, Hernández F. Lectin-gold localization of fucose residuos in human gastric mucosa. J Histochem Cytochem. 1998;46(11):1311-20.

9. Salih BA, Abasiyanik MF, Bayyurt N, Sander E. H pylori infection and other risk factors associated with peptic ulcers in Turkish patients: a retrospective study. World J Gastroenterol. 2007;13(23):3245-48.

10. Peres WA, Carmo MG, Zucoloto S, Iglesias AC, Braulio VB. Ethanol intake inhibits growth of the epithelium in the intestine of pregnant rats. Alcohol. 2004;33(2):83-9.

11. Melo-Junior MR, Machado MCFP, Araújo-Filho JLS, Patu VJRM, Beltrão EIC, Pontes-Filho NT. Avaliação histoquímica da mucosa gastrointestinal de ratos expostos ao álcool. Rev Para Med. 2006;20(4):7-12. 
12. Gargie M, Azuine MA, Lakshman MR. Chronic ethanol consumption upregulates the cytosolic and plasma membrane sialidase genes, but downregulates lysosomal membrane sialidase gene in rat liver. Metabolism. 2006;55(6):803-10.

13. Lapa FR, Gadotti VM, Missau FC, Pizzolatti MG, Marques MC, Dafré AL, Farina M, Rodrigues AL, Santos AR. Antinociceptive properties of the hydroalcoholic extract and the flavonoid rutin obtained from Polygala paniculata L. in mice. Basic Clin Pharmacol Toxicol. 2009; 104(4):306-15.

14. Martinez FE, Garcia PJ, Padovani CR, Cagnon VHA, Martinez M. Ultrastructural study of the ventral lobe of the prostate of rats submitted to experimental chronic alcoholism. Prostate. 1993;22(4):317-24.

15. Faustino SES, Stipp ACM. Efeitos do alcoolismo crônico e da desintoxicação alcóolica sobre a glândula submandibular de ratos: estudo morfométrico. J Appl Oral Sci. 2003;11(1):21-6.

16. Horvath RO, Silva TD, Calil Neto J, Nakagaki WR, Garcia JAD, Soares EA. Efeitos do alcoolismo e da desintoxicação alcoólica sobre o reparo e biomecânica óssea. Acta Ortop Bras. 2011;19(5):305-8.

17. Vela SM, Souccar C, Lima-Landman MTR, Lapa AJ. Inhibition of gastric acid secretion by the aqueous extract and purified extracts of Stachytarpheta cayennensis. Planta Med. 1997;63(1):36-9.

18. Filipini CB, Paixão DR, Ávila MAP, Flausino PA, Pereira VA, Oliveira JA, Costa AMDD, Terra FS, Soares EA. Avaliação da atividade protetora gástrica do extrato hidroalcoólico da semente de girassol em ratas. Rev Bras Clin Med. 2012;10(2):112-15.

19. Svendsen P, Hau J. Handbook of laboratory animal science. Boca Raton: CRC Press; 1984. v. 1.

20. Camilli JA, Cunha MR, Bertran CA, Kawachi EY. Sbperiosteal hydroxyapatite implants in rats submitted to ethanol ingestion. Arch Oral Biol. 2004 Sept;49(9):747-53.

21. Nyquist F, Halvosenv V, Madsen JE, Nordsletten L, Obrant KJ. Ethanol and is effects on fracture healing and bone masss in de male rats. Acta Orthop Scand. 1999;70(2):212-16.

22. Ekblad E, Mei Q, Sundler F. Innervation of the gastric mucosa. Micros ResTech. 2000;48:241-57.

23. Vimala G, Shoba FG. A Review on Antiulcer Activity of Few Indian Medicinal Plants. Int J Microbiol. 2014;2014:519-90. doi: $10.1155 / 2014 / 519590$.

24. Bhowmik D, Chiranjib, Tripathil KK, Pankaj, Kumar SKP. Recent trends of treatment and medication peptic ulcerative disorder. Int J Pharm Tech Research. 2010;2(1):970-80.

25. Malfertheiner P, Chan FK, McColl KE. Peptic ulcer disease. The Lancet. 2009;374(9699):1449-61.

26. Elliot SL, Whittler JL. Nitric oxide: A regulator of mucosal defense and injury. J Gatroenterol. 2004;33:792-803.

27. Arabski M1, Kazmierczak P, Wisniewska-Jarosinska M, Poplawski T, Klupinska G, Chojnacki J, Drzewoski J, Blasiak J. Interaction of amoxicillin with DNA in human lymphocytes and H. pylori-infected and non-infected gastric mucosa cells. Chem Biol Interact. 2005;152(1):13-24.

28. Associação Brasileiras de Estudos sobre o Álcool e outras Drogas (ABAD). Comorbidades [cited 2013 Dec 10]. Available from: http:// www.abpbrasil.org.br

29. Miller TA. Mechanism of stress-related mucosal damage. Am J Med. 1987;83(1):8-14.

30. Sairam K, Rao CHV, Babu MD, Kumar KV, Agrawal VK, Goel RK. Antiulcerogenic effect of methanolic extract of Emblica officinalis: an experimental study. J Ethnopharmacol. 2002;82(1):1-9. 